\title{
Música independente no século XXI: percalços, conquistas e desafios
}

\section{Éverly Pegoraro}

\section{Resenha}

HERSCHMANN, Micael (Org.). Nas bordas e fora

do mainstream musical: novas tendências da música independente no início do século XXI. São

Paulo: Estação das Letras e Cores, 2011. 420p.
Éverly Pegoraro I everlyp@yahoo.com.br Doutoranda em Comunicação e Cultura pela Universidade Federal do Rio de Janeiro (UFRJ). Professora do Departamento de Comunicação da Universidade Estadual do Centro-Oeste (UNICENTRO).
Se o senso comum nos diz que trabalhar com música é para os criativos, o contexto contemporâneo nos prova que também é para os corajosos, os persistentes, os versáteis, os que têm iniciativa. As reconfigurações do mercado musical das últimas décadas abriram novos horizontes para quem trabalha nesse universo. Mas junto com as possibilidades, vieram novos desafios. Dentro ou fora do mainstream, o processo de transição e reestruturação do business musical aponta uma rede cada vez mais complexa com rupturas e fissuras nos padrões hegemônicos, mostrando alternativas criativas dos atores envolvidos, possibilitando mais participação de artistas e consumidores na busca por interação, visibilidade e sustentabilidade.

Esse panorama se faz sentir intensamente junto àqueles que atuam de forma independente.

0 livro Nas bordas e fora do mainstream musical. Novas tendências da música independente no início do século XXI, organizado por Micael Herschmann, traz uma coletânea de artigos de renomados pesquisadores da Europa, dos Estados Unidos e 
do Brasil, justamente repensando continuidades e rupturas na indústria da música, apontando estratégias dos atores que têm ressignificado a palavra independente.

Entretanto, como o próprio organizador da coletânea alerta logo na introdução, com a legitimidade de quem pesquisa 0 assunto há tempos, é necessário cautela quando se traçam paralelos entre independência ou mainstream musical, pois os limites são flexíveis e ainda representam importantes referências para os atores sociais desse setor. Assim, é necessário compreender a independência no mercado musical como um conceito maleável, para não engessálo ou estigmatizá-lo, o que poderia induzir a estereótipos em um contexto altamente complexo. Até mesmo porque há conexões (diretas ou indiretas) entre indies e majors, como apontam vários autores dessa coletânea.

Além disso, o contexto de reconfigurações não significa que "tudo são rosas" para quem anda pelos caminhos da música. 0s textos selecionados por Herschmann configuram um balanço equilibrado de conquistas, desafios, crises e percalços, sem partir de uma visão ingênua ou heróica sobre ser independente.

Dessa forma, a música independente serve como eixo temático central para as duas partes nas quais a obra é dividida. Na primeira, os autores apresentam pesquisas realizadas na Europa, nos Estados Unidos e na América Latina, delineando um mapa interessante para se pensar peculiaridades de artistas inseridos em diferentes contextos. Se estamos falando de um negócio em transformação, não se poderia deixar de refletir sobre alternativas que surgem nesse processo, principalmente com iniciativas de autogestão e estratégias que se fortalecem com a web 2.0.

Diante desse cenário, George Yúdice abre a coletânea de artigos constatando a emergência de uma indústria fora do âmbito das majors, cuja participação das classes populares na produção e no consumo representa um fator primordial. 0 autor atesta uma experiência musical mais integrada à vida social com o rompimento de fronteiras sociais. Um importante ator nesse processo, com papel mais ativo e participativo, é 0 consumidor. Esse assunto é abordado por Juan Ignacio Gallego, que sustenta 0 argumento de que os próprios usuários se transformam em agentes de prescrição musical. As alterações potencializadas, sobretudo pela web 2.0, e assinaladas pelo autor concedem aos usuários novas capacidades de acesso e difusão musical, originando novos modelos de negócios pela internet e facilitando o desenvolvimento de micromídias e selos independentes.

Na segunda seção da primeira parte do livro, os autores abordam as relações entre majors e indies. Keith Negus argumenta que, para entender os rumos do rap e suas delineações enquanto gênero musical e prática cultural é preciso compreendêlo também como negócio, um complexo jogo entre 
selos pequenos, grandes companhias e a "rua". Aliás, esta última desempenhando papel primordial para 0 marketing do gênero e, simultaneamente, para reunir informações sobre mercados e consumidores aos escritórios centrais do "negócio". 0 texto traduzido faz parte do seu referencial livro Music genres and corporate cultures.

Um dos grandes desafios das independentes é justamente conseguir sustentabilidade. Luis Albornoz e Juan Ignacio Gallego mostram as estratégias das pequenas gravadoras e distribuidoras espanholas, destacando que a união de forças através do associativismo tem sido uma forma de conquistar espaço num mercado altamente competitivo e controlado pelas multinacionais. Na sequência, Micael Herschmann aponta que uma tendência inusitada tem conquistado o business da música entre 0 universo indie e major: os games musicais. 0 crescente interesse do público não mais limitado a jovens e adolescentes por esse tipo de entretenimento possibilita um modelo alternativo para o setor, novas possibilidades para artistas e bandas, além de sinalizar tendências para a compreensão das próprias culturas urbanas musicais. E para finalizar esta seção, Wayne Marshall, Raquel Rivera e Debora Hernandez apresentam o reggaeton, ressaltando não apenas a sua dimensão econômica, mas social também, reforçando os argumentos de que as mais diversas manifestações musicais não podem ser compreendidas tão somente a partir da dualidade entretenimento/consumo. $0 \mathrm{~s}$ autores mostram que esse gênero musical incita reflexões sobre questões profundas, como etnia e democracia racial.

A segunda parte da obra é dedicada ao delineamento do cenário musical independente no Brasil. Na primeira seção, Leonardo de Marchi e Marcelo Kischinhevsky refletem sobre a reintermediação dos negócios da música a partir de diferentes agentes. Ambos os textos reiteram a importância das independentes brasileiras na manutenção e expansão da diversidade musical no mercado. De Marchi analisa o papel das gravadoras independentes brasileiras em uma indústria fonográfica em rede. A partir do contexto de transformações pelos quais 0 negócio da música vem passando, 0 autor mostra que as relações entre os envolvidos na produção musical não são equilibradas, porém mais flexíveis. As gravadoras passam a ser prestadoras de serviço para os artistas. Assim, produtores independentes assumem um papel estratégico, trabalhando com diversos tipos de artistas, enquanto as grandes gravadoras se concentram em uns poucos músicos de forte apelo comercial. Kischinhevsky, por sua vez, analisa as relações entre as gravadoras independentes e as emissoras de rádio, no que se refere à promoção de artistas e músicas nas suas programações. Através de enquete realizada entre diretores, gerentes e coordenadores de programação, 0 autor aponta fatores que interferem (e até prejudicam) a diversidade nas seleções de conteúdo musical. 
A próxima seção do livro comprova a riqueza e multiplicidade cultural/musical do país, numa verdadeira viagem por cinco curiosos circuitos e cenas em diferentes regiões brasileiras. 0 fio central que conduz os textos é mostrar como os agentes envolvidos nessas dinâmicas aproveitam e se adéquam a condições econômicas regionais na busca por sustentabilidade. 0 tecnobrega do Pará e o forró do Amazonas servem de ponto de partida para Olívia Bandeira de Melo e 0ona Castro mostrarem como as tecnologias digitais propiciam alterações nas estruturas do negócio da música. As autoras argumentam que tais mudanças possibilitam novas formas de produção, distribuição e consumo adaptadas às condições regionais, assim fortalecendo cenas e facilitando o acesso do público a uma diversidade cultural diferente da oferecida pelos mercados hegemônicos.

A próxima parada é no Recife, onde Felipe Trotta reflete sobre as contradições do forró contemporâneo a partir do paradoxo da tradição rural manifesta em solo urbano. 0 autor mostra de que forma, no mercado independente do forro pé de serra, a tradição é usada como argumento discursivo de valoração simbólica para justificar investimentos públicos e privados nesse segmento. Entretanto, o autor sinaliza que tal contexto discursivo, apoiado pelo financiamento público, acaba por reificar uma visão congelada de tradição, segregando práticas artísticas e culturais que poderiam ter grande aceitação popular.
Do Recife para o estado do Rio de Janeiro: Micael Herschmann apresenta as ruas que cantam em Conservatória através do peculiar movimento seresteiro que acabou sedimentando um polo turístico local, em um ambiente musical caracterizado por afetividade e engajamento. 0 autor argumenta que a mobilização e a sociabilidade que marcam os seresteiros do município são um exemplo claro da razão sensível que os une, como diria Michel Maffesoli. São o idealismo, a paixão e os afetos deles e dos visitantes que vêm garantindo o intenso desenvolvimento local. Ao mesmo tempo, reiteram a crescente "revaloração" das "experiências". Ainda no Rio de Janeiro, Cíntia SanMartin Fernandes analisa um espaço físico em que a experiência musical também se torna 0 amálgama de sociabilidades. A autora percorreu as ruas do conhecido Polo da Praça XV, no centro da cidade, e constatou a reinvenção daquele espaço urbano e sua respectiva revitalização financeira. A música ao vivo, especialmente o samba e o choro, passaram a fazer parte do conjunto de bares e restaurantes daquele ambiente, representando uma alternativa para artistas exibirem seu trabalho. Nesse contexto, a experiência musical se torna um elemento central de ressignificação urbana e comercial, comprovando que aquelas ruas são espaços que conjugam relações econômicas e socioculturais comunitárias, como sustenta Fernandes.

A última parada é no funk carioca, com Simone Pereira de Sá e Gabriela Miranda. Elas abordam 
aspectos da cadeia de produção, circulação e consumo desse gênero musical, demonstrando que, apesar das especificidades de cada um, há aproximações entre o funk, o tecnobrega do Pará e 0 forró eletrônico do nordeste. As práticas de negócios relativamente sustentáveis e autônomas do funk articulam uma rede de DJs, MCs e a comunidade de frequentadores dos bailes. As autoras problematizam elementos desse processo, como as estratégias de comercialização da música, analisando como a apropriação tecnológica e a ligação com a comunidade são centrais para 0 mercado do funk.

A última seção da segunda parte do livro refere-se às perspectivas e aos desafios para a produção e o consumo musical. Adriana Amaral e João Pedro Wizniewsky Amaral analisam as estratégias de divulgação pelas redes sociais de dois grupos do happy rock, termo que conceitua o rock colorido pós-emo, direcionado principalmente a um público entre 10 e 15 anos. Os autores apresentam 0 estilo como representante de um novo modelo de rock independente, que se foca tanto na comunicação via mídias sociais quanto no próprio mercado. Nas duas bandas gaúchas escolhidas para análise, Amaral e Wizniewsky Amaral sinalizam a utilização de estratégias que caracterizam um hibridismo de posicionamento mercadológico, mesclando um discurso de independência com ações típicas do mainstream. Dessa forma, ao mesmo tempo em que participam de grandes festivais, as bandas se vinculam a selos independentes e disponibilizam conteúdo musical para download. 0 uso intenso das redes sociais as posiciona bem próximas do seu potencial público pré-adolescente e oportuniza que seus fãs se tornem curadores on line.

Na sequência de artigos, 0 Grupo Musicultura traz uma interessante pesquisa sobre gostos musicais dos moradores da Maré o maior conjunto de favelas do Rio de Janeiro, propiciando dados quantitativos e qualitativos sobre consumo e circulação de música naquele local. Trata-se dos resultados de um projeto exemplar justamente por aproximar universidade e comunidade, com fundamentação nos princípios do educador Paulo Freire. 0 Musicultura é um coletivo de jovens pesquisadores, a maioria moradores da Maré. São estudantes do ensino médio de escolas públicas, da Universidade Federal do Rio de Janeiro das mais diversas áreas de estudo e voluntários que se reuniram para pesquisar as práticas e experiências musicais na comunidade, dialogando com a mesma temática no Rio de Janeiro e na própria contemporaneidade como um todo. Além de ampliar as possibilidades de leitura e reflexão sobre 0 assunto, muitos resultados apontam dados inusitados e que contradizem algumas afirmações generalizantes ou simplificadas sobre consumo musical entre as populações de baixa renda.

E, para fechar uma sucessão de artigos instigantes sobre as novas tendências da música independente, Jeder Janotti Junior, Suzana Maria Dias Gonçalves e Victor de Almeida Nobre Pires nos apresentam o emblemático exemplo do cantor Wado, cuja trajetória é uma espécie de síntese das 
transformações da indústria musical, em suas potencialidades, obstáculos e fragilidades para os artistas e as relações com o mercado da música. Wado, que optou por estabelecer-se em Alagoas e pelo viés independente, já tem seu espaço reconhecido pela crítica cultural e legitimado através dos cinco discos lançados ao longo de oito anos. Ele é a prova cabal da versatilidade que se exige dos músicos contemporâneos. "Fazer música" é apenas uma etapa de uma longa jornada que envolve processos criativos, estratégias econômicas e até mesmo lógicas discursivas para enquadramento dos produtos musicais em políticas públicas de fomento à produção cultural, argumentam os autores. Como eles relatam, Wado mostra que é "possível ser alguém, mesmo que com reconhecimento restrito, morando nas periferias dos centros em que se localizam as grandes indústrias culturais". Ou, nas próprias palavras de sua canção, ele é o exemplo de quem "aperta o botão e faz funcionar a reforma agrária do ar". Essa é, aliás, uma característica acentuada do mercado musical no início de século XXI: artistas que conseguem certa legitimidade para 0 seu trabalho, ainda que distantes das "paradas de sucesso nacionais" ou dos grandes selos.

Longe de uma visão deslumbrada ou nostálgica a respeito das transformações pelas quais a indústria da música passa, o livro compõe um panorama analítico das intensas e complexas relações que se estabelecem entre músicos, consumidores e mercado. Comprova-se que a música não se transformou em apenas mais um produto da indústria cultural contemporânea. Pelo contrário, através de ações inusitadas de quem busca viver pela música, ela opera e simultaneamente reflete valores, percepções e ações de um universo cheio de ambivalências. 


\section{Expediente}

A revista E-Compós é a publicação científica em formato eletrônico da Associação Nacional dos Programas de Pós-Graduação em Comunicação (Compós). Lançada em 2004, tem como principal finalidade difundir a produção acadêmica de pesquisadores da área de Comunicação, inseridos em instituições do Brasil e do exterior.

\section{E-COMPÓS I www.e-compos.org.br I E-ISSN 1808-2599}

Revista da Associação Nacional dos Programas

de Pós-Graduação em Comunicação.

Brasília, v.15, n.2, maio/ago. 2012.

A identificação das edições, a partir de 2008 ,

passa a ser volume anual com três números.

\section{CONSELHO EDITORIAL}

Afonso Albuquerque, Universidade Federal Fluminense, Brasil Alberto Carlos Augusto Klein, Universidade Estadual de Londrina, Brasil Álvaro Larangeira, Universidade Tuiuti do Paraná, Brasi André Luiz Martins Lemos, Universidade Federal da Bahia, Brasil Ângela Freire Prysthon, Universidade Federal de Pernambuco, Brasil Angela Cristina Salgueiro Marques, Faculdade Cásper Líbero (São Paulo), Brasil Antonio Roberto Chiachiri Filho, Faculdade Cásper Líbero, Brasil Arthur Autran Franco de Sá Neto, Universidade Federal de São Carlos, Brasil Benjamim Picado, Universidade Federal Fluminense, Brasil César Geraldo Guimarães, Universidade Federal de Minas Gerais, Brasil Cristiane Freitas Gutfreind, Pontifícia Universidade Católica do Rio Grande do Sul, Brasil

Denilson Lopes, Universidade Federal do Rio de Janeiro, Brasil Eduardo Peñuela Cañizal, Universidade Paulista, Brasi Eduardo Vicente, Universidade de São Paulo, Brasil Eneus Trindade, Universidade de São Paulo, Brasil Florence Dravet, Universidade Católica de Brasília, Brasil Gelson Santana, Universidade Anhembi/Morumbi, Brasil Gislene da Silva, Universidade Federal de Santa Catarina, Brasil Guillermo Orozco Gómez, Universidad de Guadalajara Gustavo Daudt Fischer, Universidade do Vale do Rio dos Sinos, Brasil Hector Ospina, Universidad de Manizales, Colômbia Herom Vargas, Universidade Municipal de São Caetano do Sul, Brasil Inês Vitorino, Universidade Federal do Ceará, Brasil Jay David Bolter, Georgia Institute of Technology Jeder Silveira Janotti Junior, Universidade Federal de Pernambuco, Brasil John DH Downing, University of Texas at Austin, Estados Unidos José Afonso da Silva Junior, Universidade Federal de Pernambuco, Brasil José Carlos Rodrigues, Pontifícia Universidade Católica do Rio de Janeiro, Brasi José Luiz Aidar Prado, Pontifícia Universidade Católica de São Paulo, Brasil Kelly Cristina de Souza Prudêncio, Universidade Federal do Paraná, Brasil. Laan Mendes Barros, Universidade Metodista de São Paulo, Brasil
Lance Strate, Fordham University, USA, Estados Unidos

Lorraine Leu, University of Bristol, Grã-Bretanha

Lucia Leão, Pontifícia Universidade Católica de São Paulo, Brasil

Malena Segura Contrera, Universidade Paulista, Brasil

Márcio de Vasconcellos Serelle, Pontifícia Universidade Católica de Minas Gerais, Brasil

Maria Aparecida Baccega, Universidade de São Paulo e Escola Superior de Propaganda e Marketing, Brasil

Maria Ataide Malcher, Universidade Federal do Pará, Brasi

Maria das Graças Pinto Coelho, Universidade Federal do Rio Grande do Norte, Brasil

Maria Immacolata Vassallo de Lopes, Universidade de São Paulo, Brasil Maria Luiza Martins de Mendonça, Universidade Federal de Goiás, Brasi Mauro de Souza Ventura, Universidade Estadual Paulista, Brasil Mauro Pereira Porto, Tulane University, Estados Unidos Mirna Feitoza Pereira, Universidade Federal do Amazonas, Brasil Nilda Aparecida Jacks, Universidade Federal do Rio Grande do Sul, Brasil Osvando J. de Morais, Universidade de Sorocaba, Brasil Potiguara Mendes Silveira Jr, Universidade Federal de Juiz de Fora, Brasil Renato Cordeiro Gomes, Pontifícia Universidade Católica do Rio de Janeiro, Brasil Robert K Logan, University of Toronto, Canadá

Ronaldo George Helal, Universidade do Estado do Rio de Janeiro, Brasil Rose Melo Rocha, Escola Superior de Propaganda e Marketing, Brasil Rossana Reguillo, Instituto de Estudos Superiores do Ocidente, Mexico Rousiley Celi Moreira Maia, Universidade Federal de Minas Gerais, Brasil Sebastião Guilherme Albano da Costa, Universidade Federal do Rio Grande do Norte, Brasil

Simone Maria Andrade Pereira de Sá, Universidade Federal Fluminense, Brasil Tiago Quiroga Fausto Neto, Universidade de Brasília, Brasil Suzete Venturelli, Universidade de Brasília, Brasil Valerio Fuenzalida Fernández, Puc-Chile, Chile Veneza Mayora Ronsini, Universidade Federal de Santa Maria, Brasil Vera Regina Veiga França, Universidade Federal de Minas Gerais, Brasil

\section{COMISSÃO EDITORIAL}

Adriana Braga I Pontifícia Universidade Católica do Rio de Janeiro, Brasil

Felipe Costa Trotta I Universidade Federal Fluminense, Brasi

CONSULTORES AD HOC

Adriana Amaral, Universidade do Vale do Rio dos Sinos, Brasil

Ana Carolina Escosteguy, Pontifícia Universidade Católica do Rio Grande do Sul, Brasi Claudia Azevedo, Universidade Federal do Estado do Rio de Janeiro, Brasil Gisela Castro, Escola Superior de Propaganda e Marketing, Brasil Luis Queiroz, Universidade Federal da Paraíba, Brasil Rodrigo Carreiro, Universidade Federal de Pernambuco, Brasil EDIÇÃO DE TEXTO E RESUMOS I Susane Barros SECRETÁRIA EXECUTIVA I Juliana Depiné EDITORAÇÃO ELETRÔNICA I Roka Estúdio TRADUÇÃo I Sieni Campos
COMPÓS I www.compos.org.br

Associação Nacional dos Programas de Pós-Graduação em Comunicação

Presidente

Julio Pinto

Pontifícia Universidade Católica de Minas Gerais, Brasil juliopinto@pucminas.br

Vice-presidente

Itania Maria Mota Gomes

Universidade Federal da Bahia, Brasil

itania@ufba.br

Secretária-Geral

Inês Vitorino

Universidade Federal do Ceará, Brasil

inesvic@gmail.com 